\title{
Communication
}

\section{Neurotensin Agonist Attenuates Nicotine Potentiation to Cocaine Sensitization}

\author{
Paul Fredrickson ${ }^{\dagger} *$, Mona Boules ${ }^{\dagger}$, Bethany Stennett and Elliott Richelson
}

Neuropsychopharmacology Laboratory, Mayo Foundation for Medical Education and Research Mayo

Clinic Florida, 4500 San Pablo road, Jacksonville, FL 32224, USA;

E-Mails: boules.mona@mayo.edu (M.B.); richel@mayo.edu (E.R.); bastenn@gmail.com (B.S.)

$\dagger$ These authors contributed equally to this work.

* Author to whom correspondence should be addressed; E-Mail: Fredrickson.paul@mayo.edu; Tel.: +904-953-7287; Fax: +904-953-6191.

Received: 14 November 2013; in revised form: 13 January 2014 / Accepted: 14 January 2014 / Published: 22 January 2014

\begin{abstract}
Tobacco usage typically precedes illicit drug use in adolescent and young adult populations. Several animal studies suggest nicotine increases the risk for subsequent cocaine abuse, and may be a negative prognostic factor for treatment of cocaine addiction; i.e., a "gateway drug". Neurotensin (NT) is a 13-amino acid neuropeptide that modulates dopamine, acetylcholine, glutamate, and GABA neurotransmission in brain reward pathways. NT69L, a NT(8-13) analog, blocks behavioral sensitization (an animal model for psychostimulant addiction) to nicotine, and nicotine self-administration in rats. The present study tested the effect of NT69L on the potentiating effects of nicotine on cocaine-induced locomotor sensitization. Male Wistar rats were injected daily for seven days with nicotine or saline (control) followed by four daily injections of cocaine. NT69L was administered $30 \mathrm{~min}$ prior to the last cocaine injection. Behavior was recorded with the use of activity chambers. Subchronic administration of nicotine enhanced cocaine-induced behavioral sensitization in Wistar rats, consistent with an hypothesized gateway effect. These behavioral effects of cocaine were attenuated by pretreatment with NT69L. The effect of the neurotensin agonist on cocaine sensitization in the nicotine treated group indicated a possible therapeutic effect for cocaine addiction, even in the presence of enhanced behavioral sensitization induced by nicotine.
\end{abstract}


Keywords: neurotensin; nicotine; cocaine; gateway drug; rat

\section{Introduction}

Cigarette smoking has been conceptualized as a gateway to use and abuse of illicit drugs such as cocaine [1]. Whether this is causal or represents availability and cultural attitudes is as yet unproven [2]. However, animal models provide growing evidence for a "priming effect" of nicotine on reward circuitry. This priming effect may increase the risk for cocaine abuse and dependence [3,4].

Animal models of psychostimulant abuse include behavioral sensitization, conditioned place preference, drug discrimination, and self-administration [5]. Nicotine pretreatment enhances cocaine self-administration in adolescent [6-8] and in adult [9] rats. Nicotine also increases cocaine's discriminative stimulus and reinforcing effects in rhesus monkeys [10]. In another recent study [4], locomotor sensitization was increased by $98 \%$, conditioned place preference by $78 \%$, and cocaine-induced reduction in long-term potentiation was increased by $24 \%$ when nicotine was given prior to, and then concurrent with cocaine. Reversing the order of drug administration had no effect. Therefore, nicotine primed the response to cocaine, but cocaine did not have a similar effect on nicotine-induced behaviors or synaptic plasticity.

These animal studies suggest, although do not prove, that tobacco users are at increased risk for cocaine dependence, and that continued use of nicotine may be a negative prognostic factor for abstinence from cocaine. Furthermore, these studies point toward a need for therapies that target both nicotine and cocaine dependence. For the past decade, our laboratory has studied the effects of neurotensin (NT) analogs on neuropsychiatric diseases including psychostimulant abuse. One of our analogs, NT69L, an analog of NT(8-13), blocks the initiation and expression of nicotine-induced locomotor sensitization [11], and attenuates nicotine self-administration in rats [12].

NT is a neuropeptide that is closely associated with, and modulates DA [13], ACh, glutamate, and GABA neurotransmission involved in addiction and reward pathways. Local administration of NT in the prefrontal cortex (PFC) increases extracellular levels of ACh and GABA [14]. In support of these data are results with the NT agonist NT69L [15] which was developed in our laboratory. NT has also been reported to enhance GABAergic activity in rat hippocampus [16] and to reduce glutamatergic neurotransmission in dorsolateral striatum [17]. However, NT must be administered centrally to have an effect because it is easily degraded by peptidases. Our laboratory has developed a number of NT agonists that can be administered systemically and maintain the central effects of NT. The most studied of these agonists is NT69L which binds with equal affinity to the two well characterized NT receptors (NTS1 and NTS2).

Our work with the NT agonist NT69L shows that it blocks nicotine-induced sensitization $[11,18]$ and nicotine self-administration [12]. While the role of NT is strongly implicated in nicotine addiction, its role in cocaine addiction is controversial. Administration of cocaine increases NT immunoreactivity in the dorsal striatum, substantia nigra and globus pallidus [19], increases NT mRNA in the rostral striatum [20] and increases NT gene expression in the ventrolateral striatum [21]. The use of NT gene knockout mice showed that NT is not involved in cocaine mediated behavior except under certain 
conditions where the absence of endogenous NT causes a slight prolongation of the effects of cocaine [22]. The use of either NT agonists or antagonists to treat cocaine locomotor activity and locomotor sensitization gave mixed results. Administration of the NT antagonist SR48692 did not alter cocaine-induced locomotor activity [23,24] except when administered chronically and in high doses [24]. Others reported partial reversal of the expression of locomotor sensitization with SR48692 [25] or a delay in the development of cocaine sensitization when the SR compound is given prior to but not in conjunction with cocaine [26]. There is also mixed data with the use of NT agonists. Systemic administration of the nonselective NT agonist NT69L [27] or central administration of NT [24] attenuate cocaine-induced locomotor activity. However, central administration of NT(8-13) did not alter cocaine-induced locomotor activity or cocaine sensitization [28]. Biochemically, NT [24] and NT69L [29] interact with dopamine, the neurotransmitter that promotes the motivational process for both nicotine and cocaine.

The primary goal of the present study was to examine the effect of the neurotensin receptor agonist, NT69L, on nicotine-induced potentiation of cocaine locomotor sensitization.

\section{Methods}

\subsection{Animals}

Male Wistar rats ( $\mathrm{n}=4-16$ per group) weighing 200-220 $\mathrm{g}$ at the start of the experiments were used. Animals were housed in temperature controlled rooms with free access to food and water. All animal procedures were approved by Mayo Clinic Institutional Animal Care and Use Committee.

\subsection{Treatments}

The rats were divided into 2 groups ( $\mathrm{n}=16$ per group) (Figure 1). One group was injected with nicotine $(0.35 \mathrm{mg} / \mathrm{kg}$, s.c.) twice daily, (8:30 AM and 4:30 PM) for 7 days and the other group was injected at the same time with saline. Each group was then subdivided into 2 groups. One group was injected with cocaine $(20 \mathrm{mg} / \mathrm{kg}$ i.p.) and the other with saline daily for four days. The effect of NT69L (1 mg/kg i.p.) was tested in half the animals in each group. To test for the effect of NT69L on cocaine challenge, the cocaine-treated animals in both the nicotine and the saline groups were given one dose of cocaine (20 mg/kg i.p.) $48 \mathrm{~h}$ after the last cocaine injection. Figure 1 shows a summary of the treatments.

\subsection{Behavioral Testing}

Locomotor activity was determined in a Plexiglas Opto-Varimex activity chamber (Columbus, OH, USA) equipped with infrared photocell emitters and detectors. The rats were acclimated in the room for $1 \mathrm{~h}$ and then placed in the activity chambers. Baseline activity was recorded for $1 \mathrm{~h}$ after which animals were injected with saline, nicotine, or cocaine. Activity was recorded as distance travelled in $\mathrm{cm}$ every $10 \mathrm{~min}$ in a $2 \mathrm{~h}$ period. To test the effects of NT69L, animals were injected with NT69L $(1 \mathrm{mg} / \mathrm{kg}$ i.p.) $30 \mathrm{~min}$ prior to the injection of cocaine. 
Figure 1. Experimental design.

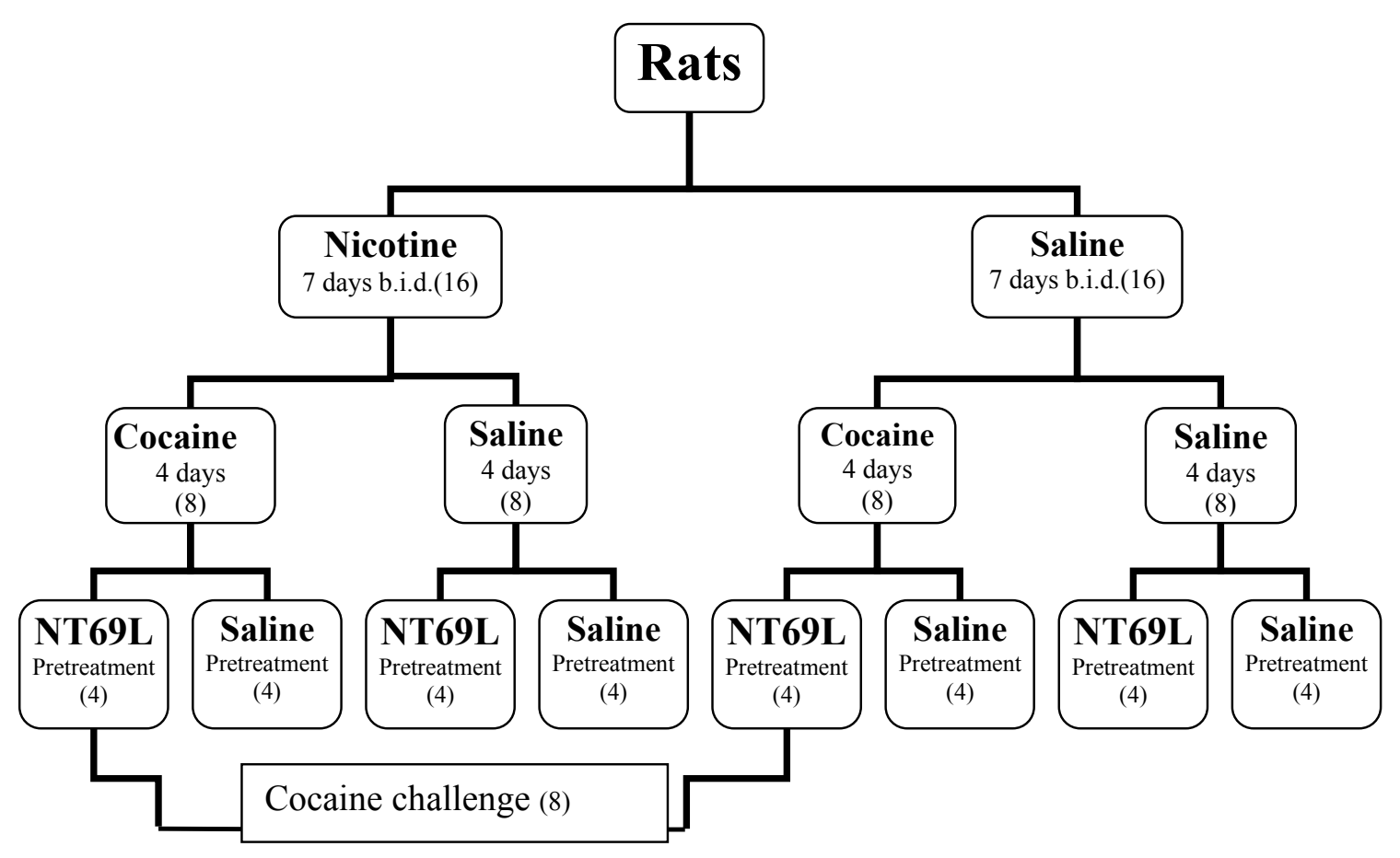

$(n)=$ number of animals per group.

\subsection{Drugs}

NT69L was synthesized by Mayo Clinic Chemistry Core facility as described previously [30]. NT69L was administered at a dose of $1 \mathrm{mg} / \mathrm{kg}$ i.p. The dose of NT69L was based on results from our previous studies [12,27,29]

Nicotine hydrogen tartrate salt and cocaine were purchased from Sigma Chemical Co. (St Louis, MO, USA) and were dissolved in sterile physiological saline ( $0.9 \%$ sodium chloride). Nicotine was administered at a dose of $0.35 \mathrm{mg} / \mathrm{kg}$ s.c., and cocaine was administered at a dose of $20 \mathrm{mg} / \mathrm{kg}$ i.p., based on results from on our previous studies for nicotine [11,18] and for cocaine [27].

\subsection{Statistical Analysis}

One-way analysis of variance (ANOVA) was used to analyze the data. Individual group comparisons were carried out using the Holm-Sidak test with the use of SigmaStat 2.0 software (SPSS, Inc., Chicago, IL, USA), with $P<0.05$ being considered significant.

\section{Results}

There was no significant difference in locomotor activity between animals treated with saline once (acute) or daily for seven days $(P=0.428)$, thus the two groups were averaged and depicted as "saline" group. 


\subsection{Effect of Nicotine on Locomotor Activity}

Acute and 7 daily treatments twice per day with nicotine $(0.35 \mathrm{mg} / \mathrm{kg}$ s.c. $)$ significantly $\left(\mathrm{F}_{4,46}=11.339, P<0.001\right)$ increased locomotor activity. Injection of nicotine significantly increased locomotor activity as compared to baseline and saline control, $P<0.05$. Repeated injection of nicotine further increased locomotor activity as compared to acute injection $(P<0.03)$, results that are indicative of sensitization (Figure 2a).

\subsection{Effect of NT69L on Cocaine-Induced Sensitization}

One way ANOVA show that cocaine treatment $(20 \mathrm{mg} / \mathrm{kg}$ i.p. $)$ significantly increased locomotor activity $\left(\mathrm{F}_{5,47}=43.462, P<0.001\right)$. Acute injection of cocaine significantly increased locomotor activity as compared to baseline and saline controls $(P<0.001)$. Daily injection of cocaine for four days further increased locomotor activity, results that are indicative of sensitization $(P<0.01)$. Pretreatment of cocaine-sensitized rats with NT69L $(1 \mathrm{mg} / \mathrm{kg}$ i.p.) attenuated cocaine-induced locomotor activity $(P<0.001)$ (Figure $2 b)$.

\subsection{Effect of Chronic Nicotine Treatment on Subsequent Cocaine Sensitization}

One-way ANOVA $\left(\mathrm{F}_{2,24}=52.933, P<0.001\right)$ show that pretreatment with nicotine $(0.35 \mathrm{mg} / \mathrm{kg}$ s.c.) twice daily for seven days significantly increased cocaine-induced locomotor sensitization as compared to saline pretreated animals $(P<0.032)$. As expected, injection of cocaine $(20 \mathrm{mg} / \mathrm{kg}$ i.p. $)$ in the nicotine and saline pretreated animals, significantly increased locomotor activity as compared to baseline activity $(P<0.001)$, Figure 2 c.

Figure 2. Effects of NT69L on locomotor activity in rats exposed to nicotine and cocaine. Male Wistar rats ( $n=4-16$ per group) were injected twice daily for seven days with nicotine $(0.35 \mathrm{mg} / \mathrm{kg}$ s.c. $)$ or saline control followed by four daily injections of cocaine (20 $\mathrm{mg} / \mathrm{kg}$ i.p.). Cocaine challenge (20 mg/kg i.p.) was administered $48 \mathrm{~h}$ after the last cocaine injection. NT69L (1 mg/kg i.p.) was administered $30 \mathrm{~min}$ prior to cocaine injection on test days. Behavior was recorded with the use of activity chambers. (a) Effect of chronic nicotine injection on locomotor activity; (b) Effect of NT69L on cocaine-induced locomotor sensitization; (c) Effect of chronic nicotine pretreatment on subsequent cocaine sensitization; (d) Effect of NT69L on expression of nicotine-enhanced cocaine sensitization and cocaine challenge.

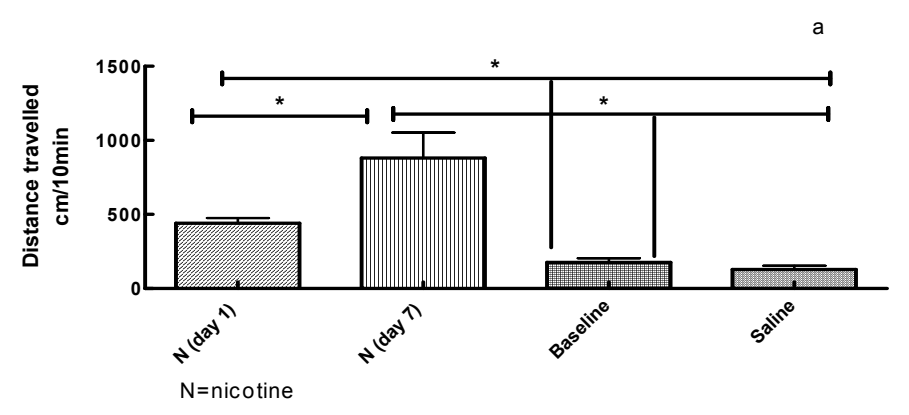


Figure 2. Cont.

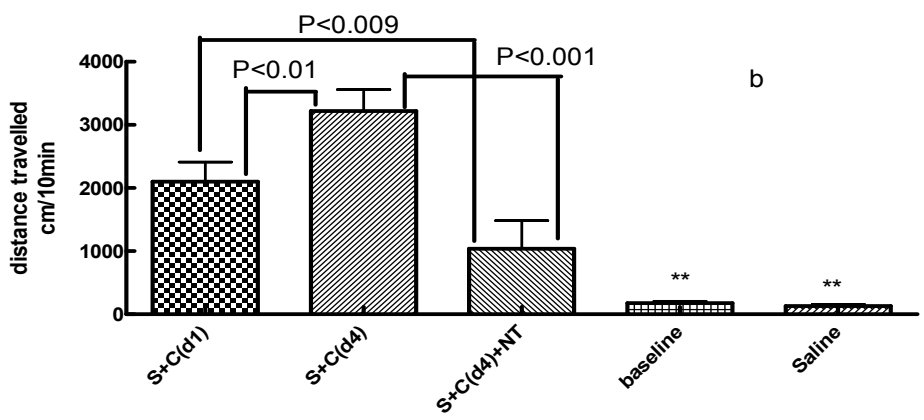

**Significantly different from cocaine treated groups, $\mathrm{P}<0.001$

$S+C(d 1)=$ saline + cocaine, day 1

$\mathrm{S}+\mathrm{C}(\mathrm{d} 4)=$ saline + cocaine, day 4 NT=NT69L
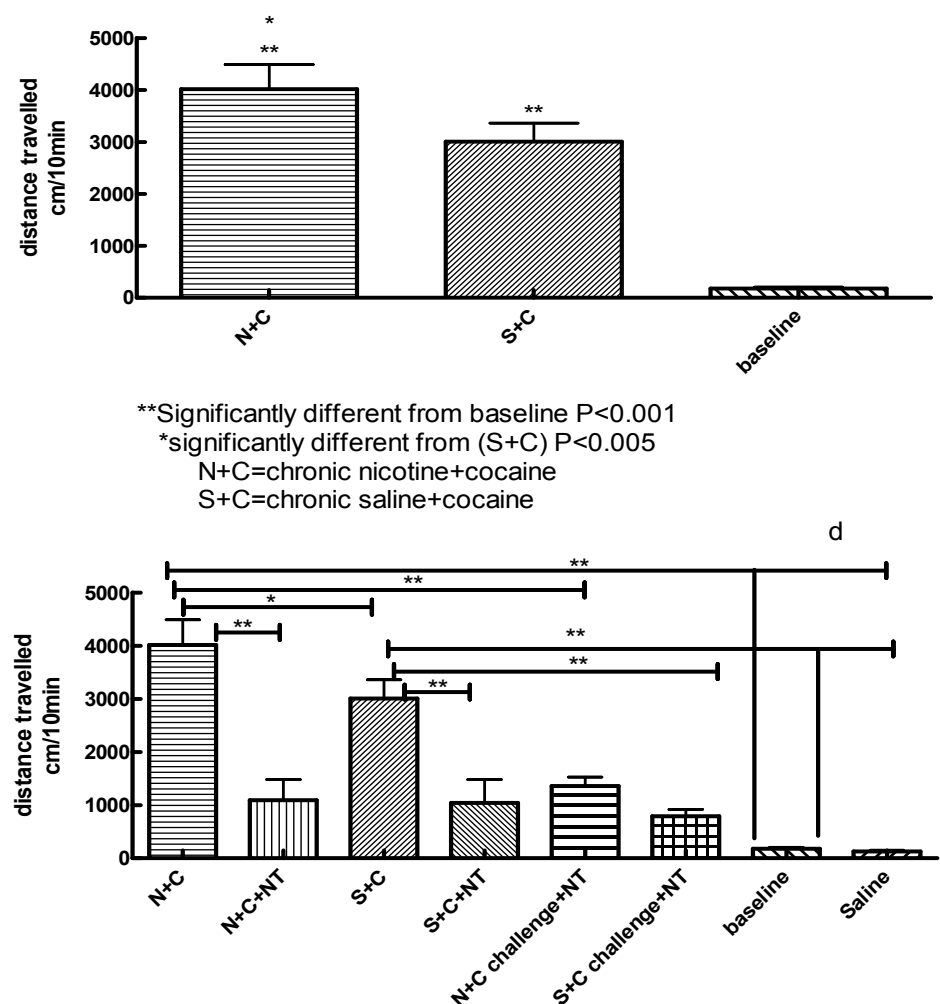

**significantly different $\mathrm{P}<0.001$

*significantly different $P<0.005$

$\mathrm{N}+\mathrm{C}=$ chronic nicotine + cocaine

$\mathrm{S}+\mathrm{C}=$ chronic saline + cocaine

$\mathrm{N}+\mathrm{C}$ challenge $+\mathrm{NT}=$ chronic nicotine + cocaine challenge $+\mathrm{NT}$

$\mathrm{S}+\mathrm{C}$ challenge $+\mathrm{NT}=$ chronic saline + cocaine challenge $+\mathrm{NT}$

NT $=$ NT69L

\subsection{Effect of NT69L on Expression of Nicotine-Enhanced Cocaine-Induced Sensitization and}

\section{Cocaine Challenge}

One-way ANOVA show significant effect of treatment $\left(\mathrm{F}_{7,55}=40.332, P<0.001\right)$. Further pairwise comparisons show that daily administration of nicotine significantly increased cocaine-induced locomotor sensitization $(P<0.005)$ as compared with daily saline. Pretreatment with NT69L $(1 \mathrm{mg} / \mathrm{kg}$ 
i.p.) significantly attenuated cocaine-induced locomotor activity in both the nicotine- $(P<0.001)$ and the saline- $(P<0.001)$ pretreated animals. Additionally, NT69L markedly reduced locomotor activity after cocaine challenge in both the nicotine- $(P<0.001)$ and the saline- $(P<0.001)$ pretreated animals. All nicotine and cocaine treated animals showed increased locomotor activity as compared to baseline activity (prior to treatment) and saline treated animals $(P<0.001)$. There was no significant difference between saline treated animals and baseline activity of all tested animals $(P=0.973)$, Figure $2 \mathrm{~d}$.

\section{Discussion}

Locomotor sensitization is a robust and readily assayed effect of psychostimulants. It measures the animal's gradually increasing behavioral and motivational response to a fixed drug dose, assayed as an increase in locomotor activity [4] (for review, Robinson and Berridge, [31]). Locomotor sensitization has been shown in rodents to be associated with augmented drug reward and increased vulnerability to relapse [31].

Locomotor sensitization is separated into two components: induction and expression. Induction of sensitization is the progressive increase in locomotor activity during drug treatment, while the expression of sensitization is demonstrated following challenge with cocaine after a drug-free period [32]. Our results show that the rats developed locomotor sensitization after repeated injections of nicotine, as we previously showed [11]. Additionally, and similar to previous studies [7,8,33,34], both induction and expression of locomotor sensitization were observed in the present study after four daily injections of cocaine and cocaine challenge. Our group has reported that NT69L blocks the initiation and expression of nicotine sensitization [11], as well as nicotine self-administration [12].

In the present study NT69L attenuated the expression of cocaine sensitization. Sub-chronic injection of nicotine enhanced cocaine-induced sensitization, results that are consistent with the "gateway" effect of nicotine on cocaine abuse [4]. Prior studies showed cross-sensitization of nicotine and cocaine-induced locomotion [35,36]. In a study of adolescent rats designed to model smoking behaviors of human adolescents, injections of low dose nicotine $(0.06 \mathrm{mg} / \mathrm{kg})$ did not produce behavioral sensitization. However, low dose nicotine did enable locomotor sensitization to cocaine that was not seen in control animals [8]. The difference in the results between our study and that of the McQuown group might be due to: (1) difference in the rat species used; (2) age difference in animals (adolescent versus adults); (3) dose and route of administration of nicotine; and (4) dose and route of administration of cocaine. The effect of NT69L on cocaine sensitization in the nicotine treated group indicates its possible therapeutic effect even with the enhanced locomotor sensitization induced by nicotine.

Cocaine dependence results from drug-induced neural adaptations in mesocorticolimbic dopamine pathways and associated glutamatergic circuitry [37]. Induction of sensitization requires activation of dopaminergic and glutamatergic neurotransmission in the ventral tegmental area $[38,39]$ and glutamatergic input from the prefrontal cortex [40,41]. Expression of sensitization is primarily attributed to neurochemical changes in the nucleus accumbens [42] leading to cocaine-induced increase in dopamine and glutamate release in the nucleus accumbens $[34,43,44]$.

Our previous studies [29] show that pretreatment with NT69L attenuates the acute nicotine evoked increases in dopamine in the nucleus accumbens shell and reverses the increase in dopamine levels in 
the nucleus accumbens core. NT69L also modulates tyrosine hydroxylase, dopamine D1 and D2 receptor mRNA levels in the striatum, prefrontal cortex, and ventral tegmental area in rats that self-infused nicotine [12]. In addition to modulating dopaminergic neurotransmission, NT69L modulates the glutamatergic neurotransmission that is involved in the addiction of cocaine and other drugs such as alcohol ([45]; Boules et al., unpublished data).

NT69L's attenuation of some of the biochemical effects of acute and chronic nicotine is consistent with this peptide's attenuation of nicotine-induced behavioral effects. Findings by Levine et al. [4] suggest that nicotine replacement therapy given to cocaine addicts for smoking cessation may undermine efforts to treat cocaine addiction. Novel therapies, such as neurotensin analogs, therefore, warrant additional study.

\section{Conclusions}

Subchronic administration of nicotine enhanced cocaine-induced behavioral sensitization in Wistar rats, consistent with an hypothesized gateway effect. These behavioral effects of cocaine were attenuated by pretreatment with NT69L. The data presented here are further evidence for a role for NT69L or other neurotensin receptor agonists to treat nicotine addiction, and provide preliminary support that these compounds may be useful for management of cocaine addiction.

\section{Acknowledgments}

This work was supported by Mayo Foundation for Medical Education and Research and grant number 2KF01 04NIR-02 from the Florida Department of Health to Mona Boules.

\section{Conflicts of Interest}

Paul Fredrickson, Mona Boules and Elliott Richelson were issued US patent number 7,087,575, 8 August 2006 titled "Treating the Effect of Nicotine".

\section{References}

1. Biederman, J.; Monuteaux, M.C.; Mick, E.; Wilens, T.E.; Fontanella, J.A.; Poetzl, K.M.; Kirk, T.; Masse, J.; Faraone, S.V. Is cigarette smoking a gateway to alcohol and illicit drug use disorders? A study of youths with and without attention deficit hyperactivity disorder. Biol. Psychiatry 2006, 59, 258-264.

2. Degenhardt, L.; Dierker, L.; Chiu, W.T.; Medina-Mora, M.E.; Neumark, Y.; Sampson, N.; Alonso, J.; Angermeyer, M.; Anthony, J.C.; Bruffaerts, R.; et al. Evaluating the drug use "gateway" theory using cross-national data: Consistency and associations of the order of initiation of drug use among participants in the WHO World Mental Health Surveys. Drug Alcohol Depend. 2010, 108, 84-97.

3. Volkow, N.D. Epigenetics of nicotine: Another nail in the coughing. Sci. Transl. Med. 2011, 3, doi:10.1126/scitranslmed.3003278. 
4. Levine, A.; Huang, Y.; Drisaldi, B.; Griffin, E.A., Jr.; Pollak, D.D.; Xu, S.; Yin, D.; Schaffran, C.; Kandel, D.B.; Kandel, E.R. Molecular mechanism for a gateway drug: Epigenetic changes initiated by nicotine prime gene expression by cocaine. Sci. Transl. Med. 2011, 3, doi:10.1126/scitranslmed.3003062.

5. Niwa, M.; Yan, Y.; Nabeshima, T. Genes and molecules that can potentiate or attenuate psychostimulant dependence: Relevance of data from animal models to human addiction. Ann. N. Y. Acad. Sci. 2008, 1141, 76-95.

6. McMillen, B.A.; Davis, B.J.; Williams, H.L.; Soderstrom, K. Periadolescent nicotine exposure causes heterologous sensitization to cocaine reinforcement. Eur. J. Pharmacol. 2005, 509, 161-164.

7. McQuown, S.C.; Belluzzi, J.D.; Leslie, F.M. Low dose nicotine treatment during early adolescence increases subsequent cocaine reward. Neurotoxicol. Teratol. 2007, 29, 66-73.

8. McQuown, S.C.; Dao, J.M.; Belluzzi, J.D.; Leslie, F.M. Age-dependent effects of low-dose nicotine treatment on cocaine-induced behavioral plasticity in rats. Psychopharmacology (Berl.) 2009, 207, 143-152.

9. Collins, S.L.; Izenwasser, S. Chronic nicotine differentially alters cocaine-induced locomotor activity in adolescent $v s$. adult male and female rats. Neuropharmacology 2004, 46, 349-362.

10. Mello, N.K.; Newman, J.L. Discriminative and reinforcing stimulus effects of nicotine, cocaine, and cocaine + nicotine combinations in rhesus monkeys. Exp. Clin. Psychopharmacol. 2011, 19, 203-214.

11. Fredrickson, P.; Boules, M.; Yerbury, S.; Richelson, E. Novel neurotensin analog blocks the initiation and expression of nicotine-induced locomotor sensitization. Brain Res. 2003, 979, 245-248.

12. Boules, M.; Oliveros, A.; Liang, Y.; Williams, K.; Shaw, A.; Robinson, J.; Fredrickson, P.; Richelson, E. A neurotensin analog, NT69L, attenuates intravenous nicotine self-administration in rats. Neuropeptides 2011, 45, 9-16.

13. Bissette, G.; Nemeroff, C.B. Neurotensin and the mesocorticolimbic dopamine system. Ann. N. Y. Acad. Sci. 1988, 537, 397-404.

14. Petkova-Kirova, P.; Rakovska, A.; Della Corte, L.; Zaekova, G.; Radomirov, R.; Mayer, A. Neurotensin modulation of acetylcholine, GABA, and aspartate release from rat prefrontal cortex studied in vivo with microdialysis. Brain Res. Bull. 2008, 77, 129-135.

15. Prus, A.J.; Huang, M.; Li, Z.; Dai, J.; Meltzer, H.Y. The neurotensin analog NT69L enhances medial prefrontal cortical dopamine and acetylcholine efflux: Potentiation of risperidone-, but not haloperidol-, induced dopamine efflux. Brain Res. 2007, 1184, 354-364.

16. Li, S.; Geiger, J.D.; Lei, S. Neurotensin enhances GABAergic activity in rat hippocampus CA1 region by modulating L-type calcium channels. J. Neurophysiol. 2008, 99, 2134-2143.

17. Yin, H.H.; Adermark, L.; Lovinger, D.M. Neurotensin reduces glutamatergic transmission in the dorsolateral striatum via retrograde endocannabinoid signaling. Neuropharmacology 2008, 54, 79-86.

18. Fredrickson, P.; Boules, M.; Yerbury, S.; Richelson, E. Blockade of nicotine-induced locomotor sensitization by a novel neurotensin analog in rats. Eur. J. Pharmacol. 2003, 458, 111-118. 
19. Alburges, M.E.; Hoonakker, A.J.; Horner, K.A.; Fleckenstein, A.E.; Hanson, G.R. Methylphenidate alters basal ganglia neurotensin systems through dopaminergic mechanisms: A comparison with cocaine treatment. J. Neurochem. 2011, 117, 470-478.

20. Adams, D.H.; Hanson, G.R.; Keefe, K.A. Differential effects of cocaine and methamphetamine on neurotensin/neuromedin $\mathrm{N}$ and preprotachykinin messenger RNA expression in unique regions of the striatum. Neuroscience 2001, 102, 841-851.

21. Betancur, C.; Rostene, W.; Berod, A. Chronic cocaine increases neurotensin gene expression in the shell of the nucleus accumbens and in discrete regions of the striatum. Brain Res. Mol. Brain Res. 1997, 44, 334-340.

22. Hall, F.S.; Centeno, M.; Perona, M.T.; Adair, J.; Dobner, P.R.; Uhl, G.R. Effects of neurotensin gene knockout in mice on the behavioral effects of cocaine. Psychopharmacology (Berl.) 2012, 219, 35-45.

23. Ramos-Ortolaza, D.L.; Negron, A.; Cruz, D.; Falcon, E.; Iturbe, M.C.; Cajigas, M.H.; Maldonado-Vlaar, C.S. Intra-accumbens shell injections of SR48692 enhanced cocaine self-administration intake in rats exposed to an environmentally-elicited reinstatement paradigm. Brain Res. 2009, 1280, 124-136.

24. Robledo, P.; Maldonado, R.; Koob, G.F. Neurotensin injected into the nucleus accumbens blocks the psychostimulant effects of cocaine but does not attenuate cocaine self-administration in the rat. Brain Res. 1993, 622, 105-112.

25. Felszeghy, K.; Espinosa, J.M.; Scarna, H.; Berod, A.; Rostene, W.; Pélaprat, D. Neurotensin receptor antagonist administered during cocaine withdrawal decreases locomotor sensitization and conditioned place preference. Neuropsychopharmacology 2007, 32, 2601-2610.

26. Horger, B.A.; Taylor, J.R.; Elsworth, J.D.; Roth, R.H. Preexposure to, but not cotreatment with, the neurotensin antagonist SR 48692 delays the development of cocaine sensitization. Neuropsychopharmacology 1994, 11, 215-222.

27. Boules, M.; Warrington, L.; Fauq, A.; McCormick, D.; Richelson, E. A novel neurotensin analog blocks cocaine- and D-amphetamine-induced hyperactivity. Eur. J. Pharmacol. 2001, 426, 73-76.

28. Torregrossa, M.M.; Kalivas, P.W. Neurotensin in the ventral pallidum increases extracellular gamma-aminobutyric acid and differentially affects cue- and cocaine-primed reinstatement. J. Pharmacol. Exp. Ther. 2008, 325, 556-566.

29. Liang, Y.; Boules, M.; Shaw, A.M.; Williams, K.; Fredrickson, P.; Richelson, E. Effect of a novel neurotensin analog, NT69L, on nicotine-induced alterations in monoamine levels in rat brain. Brain Res. 2008, 1231, 6-15.

30. Fauq, A.H.; Hong, F.; Cusack, B.; Tyler, B.M.; Pang, Y.P.; Richelson, E. Synthesis of (2S)-2amino-3-(1H-4-indolyl) propanoic acid, a novel trryptophan analog for structural modification of bioactive peptides. Tetrahedron: Asymmetry 1998, 9, 4127-4134.

31. Robinson, T.E.; Berridge, K.C. The neural basis of drug craving: An incentive-sensitization theory of addiction. Brain Res. Brain Res. Rev. 1993, 18, 247-291.

32. Robinson, T.E.; Berridge, K.C. Addiction. Annu. Rev. Psychol. 2003, 54, 25-53.

33. Laviola, G.; Wood, R.D.; Kuhn, C.; Francis, R.; Spear, L.P. Cocaine sensitization in periadolescent and adult rats. J. Pharmacol. Exp. Ther. 1995, 275, 345-357. 
34. Pierce, R.C.; Bell, K.; Duffy, P.; Kalivas, P.W. Repeated cocaine augments excitatory amino acid transmission in the nucleus accumbens only in rats having developed behavioral sensitization. J. Neurosci. 1996, 16, 1550-1560.

35. Kelley, B.M.; Rowan, J.D. Long-term, low-level adolescent nicotine exposure produces dose-dependent changes in cocaine sensitivity and reward in adult mice. Int. J. Dev. Neurosci. 2004, 22, 339-348.

36. Jutkiewicz, E.M.; Nicolazzo, D.M.; Kim, M.N.; Gnegy, M.E. Nicotine and amphetamine acutely cross-potentiate their behavioral and neurochemical responses in female Holtzman rats. Psychopharmacology (Berl.) 2008, 200, 93-103.

37. Thomas, M.J.; Kalivas, P.W.; Shaham, Y. Neuroplasticity in the mesolimbic dopamine system and cocaine addiction. Br. J. Pharmacol. 2008, 154, 327-342.

38. Kalivas, P.W.; Alesdatter, J.E. Involvement of N-methyl-D-aspartate receptor stimulation in the ventral tegmental area and amygdala in behavioral sensitization to cocaine. J. Pharmacol. Exp. Ther. 1993, 267, 486-495.

39. Dunn, J.M.; Inderwies, B.R.; Licata, S.C.; Pierce, R.C. Repeated administration of AMPA or a metabotropic glutamate receptor agonist into the rat ventral tegmental area augments the subsequent behavioral hyperactivity induced by cocaine. Psychopharmacology (Berl.) 2005, 179, 172-180.

40. Wolf, M.E.; Dahlin, S.L.; Hu, X.T.; Xue, C.J.; White, K. Effects of lesions of prefrontal cortex, amygdala, or fornix on behavioral sensitization to amphetamine: Comparison with N-methyl-D-aspartate antagonists. Neuroscience 1995, 69, 417-439.

41. Pierce, R.C.; Kalivas, P.W. A circuitry model of the expression of behavioral sensitization to amphetamine-like psychostimulants. Brain Res. Brain Res. Rev. 1997, 25, 192-216.

42. Vanderschuren, L.J.; Kalivas, P.W. Alterations in dopaminergic and glutamatergic transmission in the induction and expression of behavioral sensitization: A critical review of preclinical studies. Psychopharmacology (Berl.) 2000, 151, 99-120.

43. Reid, M.S.; Berger, S.P. Evidence for sensitization of cocaine-induced nucleus accumbens glutamate release. Neuroreport 1996, 7, 1325-1329.

44. Li, Y.; Hu, X.T.; Berney, T.G.; Vartanian, A.J.; Stine, C.D.; Wolf, M.E.; White, F.J. Both glutamate receptor antagonists and prefrontal cortex lesions prevent induction of cocaine sensitization and associated neuroadaptations. Synapse 1999, 34, 169-180.

45. Li, Z.; Boules, M.; Richelson, E. NT69L blocks ethanol-induced increase of dopamine and glutamate levels in striatum of mouse. Neurosci. Lett. 2011, 487, 322-324.

(C) 2014 by the authors; licensee MDPI, Basel, Switzerland. This article is an open access article distributed under the terms and conditions of the Creative Commons Attribution license (http://creativecommons.org/licenses/by/3.0/). 